\title{
SDZ MRL 953, a novel synthetic lipid A analogue, induces tolerance to the lethal effects of endotoxin and enhances nonspecific immunity
}

\author{
Charles Lam, PhD, MrC Pathol, Eberhard Schütze, DVM, EMmanuel QuakyI, DVM, PhD, \\ EKKE LIEHL, PHD, PETER STÜTZ, PHD
}

\begin{abstract}
C Lam, E Schütze, E GuAKYI, E LIEHL, P Stütz. SDZ MRL 953, a novel synthetic lipid A analogue, induces tolerance to the lethal effects of endotoxin and enhances nonspecific immunity. Can J Infect Dis 1992;3(Suppl B):94B-100B. Despite the availability of potent antimicrobials, shock due to Gram-negative rod sepsis remains an important clinical concern in immunosuppressed patients. Current strategies for treating septic shock by removal of endotoxin (lipopolysaccharides [LPS]) or putative mediators have only been partially effective. An attractive alternative appears to be the induction of hyporesponsiveness to LPS by synthetic lipid A analogues. SDZ MRL 953, a novel prototype of lipid A analogues, was examined for its ability to induce early-phase tolerance against experimental endotoxemia in mice following single or multiple administrations 2,24 , or $72 \mathrm{~h}$ before challenge. The analogue protected mice against a lethal dose of LPS or infections in a time- and dose-dependent manner. Maximum effects were observed in animals pretreated with SDZ MRL 953 on three consecutive days before the LPS challenge or microbial inoculation. To examine the mechanisms involved, peritoneal macrophages from the tolerant mice were monitored ex vivo for the release of tumour necrosis factor (TNF) and killing of an isolate of Escherichia coli. It was found that macrophages from endotoxin-tolerant mice produced only a fraction of the TNF released by cells from control groups in response to LPS. However, the killing of $E$ coli by the macrophages was enhanced. In conclusion, SDZ MRL 953 may have a prophylactic potential in reducing the risk of endotoxic shock in traumatized or in myelosuppressed patients.
\end{abstract}

Key Words: Endotoxin tolerance, Resistance to infection, SDZ MRL 953

\section{Un novel analogue synthétique du lipid A, le SDZ MRL 953, induit la tolérance aux} effets létaux de l'endotoxine et améliore l'immunité non-spécifique

RÉSUMÉ: En dépit de la disponibilité d'antimicrobiens puissants, le choc dû à une infection à Gram-négatif demeure une préoccupation clinique importante chez les patients immuno-supprimés. Les stratégies actuelles pour traiter le choc septique par la neutralisation d'endotoxines (LPS) ou de médiateurs potentiels n'ont été que partiellement efficaces. Une solution de rechange attrayante serait de reduire la réponse aux LPS à l'aide d'analogues synthétiques des lipid A. Le SDZ MRL 953, un nouveau prototype d'analogue de lipid A administré en une ou plusieurs doses a été investigué pour savoir s'il pouvait induire une tolérance à l'endototoxine au début d'une endotoxémie expérimentale chez la souris. Le lipid A a été administré 2 


\begin{abstract}
heures, 24 heures ou 72 heures avant l'épreuve de provocation. L'analogue a protégé les souris contre une dose létale de LPS ou contre les infections. L'effet dêpendait de la dose et des horaires d'administration du médicament. L'effet maxima a été observê chez les animaux pré-traités avec le SDZ MRL 953, trois jours consécutifs avant l'épreuve de provocation ou l'inoculation des microbes. Pour connaitre le mécanisme d'action du lipid A, la liberation du facteur de nécrose tumorale et de l'élimination d'un pathogene l'Escherichia coli des macrophages péritonéaux de souris tolérantes ont été étudies. On a cru observer que les macrophages péritonéaux extraits de souris tolérantes aux endotoxines n'ont produit qu'une fraction du facteur de nécrose tumorale libéré par les cellules des groupes témoins en réponse aux LPS. De plus, l'élimination de E coli par les macrophages s'est trouvée améliorée. En conclusion, le SDZ MRL 951 pourrait avoir un potentiel au niveau prophylactique en réduisant le risque de choc endotoxique chez des patients polytraumatisés ou myélosupprimés.
\end{abstract}

$\mathrm{G}$ RAM-NEGATIVE BACTERIA REMAIN THE LEADING CAUSE OF fatal infections in immunosuppressed patients despite the availability of potent antimicrobials and advances in supportive care (1-3). Increasing evidence shows that the lethality of the infection is independent of bacterial viability but is induced by an over-exuberant production of host cytokines following interaction of macrophages with lipopolysaccharides (LPS) and other cell wall components released from the cell envelope of viable or dead Gram-negative bacteria (3-6). Therefore, a successful strategy for treating Gramnegative rod sepsis should, in addition to the use of the appropriate antibiotics, also control the production of pro-inflammatory mediators by macrophages to amounts that provide only beneficial immunostimulatory effects $(6,7)$. A potential approach which has not yet been evaluated therapeutically in myelosuppressed patients at high risk of developing sepsis, appears to be the induction of early-phase tolerance to LPS. The development of LPS tolerance by daily administration of nonlethal doses of LPS to human subjects and experimental animals (8) has recently been described. It is also known that macrophages from tolerant animals exhibit a decreased production of tumour necrosis factor (TNF), a putative mediator of the lethal effects of septicemia and endotoxin (9-12). However, the overt toxicity of LPS has precluded its exploitation for prophylactic therapy in patients at high risk of developing Gram-negative infections.

The elucidation of the correct structure of lipid A (13) has led to the availability of a number of chemically defined lipid A partial structures (14). The purpose of this study was to determine whether SDZ MRL 953 (Figure 1), a prototype of a lipid A partial structure analogue with an increased therapeutic index in experimental infections $(15,16)$, is endowed with the ability of LPS or lipid A to induce tolerance to the lethal effects of LPS without antagonizing its reported ability to enhance host resistance.

\section{MATERIALS AND METHODS}

Test substances: SDZ MRL 953, 2-deoxy-3,4-bis-OI(R)-3-hydroxy-tetradecanoyI]-2-[(R)-3-hydroxytetrade-c anoylamido]-1-O-phosphono- $\alpha$-D-glucopyranose as a monotris salt (Figure 1), was synthesized at Sandoz
Forschungsinstitut, Vienna, Austria and purified using Sephadex LH 20 column to at least 99\% purity as assessed by reverse phase high performance liquid chromatography. LPS was a water-phenol extract of Salmonella abortus equi (Sigma Chemical Co, Deisenhofen, Germany). Stock solutions of the lipid A analogue and LPS were prepared by sonicating $1 \mathrm{mg}$ in $10 \mu \mathrm{L}$ of ethanol for about $1 \mathrm{~min}$. During further sonication, up to $1 \mathrm{~mL}$ of sterile pyrogen-free isotonic glucose solution $(5.4 \%)$ was added dropwise. The slightly opalescent solutions had a pH of about 7.3 and were chemically stable at room temperature for weeks. For use, the stock solutions were diluted to the required concentrations with the appropriate buffers or culture media.

Animals: Female mice $\left(\mathrm{B}_{6} \mathrm{D}_{2} \mathrm{~F}_{1}\right.$, and $\left.\mathrm{C} 57 \mathrm{BL} / 6\right)$ weighing 18 to 20 g were obtained from Charles River Laboratories (Wiga, Sulzfeld, Germany) and maintained on SFIs standard diet with water ad libitum.

Pathogenic bacteria: Escherichia coli $\Delta 120$ and Staphylococcus aureus $\Delta 113$ were from the SFI stock culture collection. The pathogens were cultivated overnight in tryptic soy broth (Difco, Michigan) and diluted in pyrogen free physiological saline (Heilmittelwerke, Vienna, Austria) to required colony forming units (cfu) as determined from a plot of optical density at $600 \mathrm{~nm}$ against viable counts.

Induction of tolerance and lavage of elicited macrophages: To obtain peritoneal macrophages, $2 \mathrm{~mL}$ of thioglycolate broth (Difco) was injected into the peritoneal cavity on day 4 (before peritoneal lavage). On days 3 through day 1 before lavage, groups of six mice received either single or multiple intraperitoneal injections of serial dilutions of the test substances in $0.2 \mathrm{~mL}$ amounts. On day 0 , the animals were killed with carbon dioxide gas and the peritoneal cavity lavaged with 25 mL volumes of Hanks' balanced salt solution (HBSS) without calcium and magnesium, (Gibco Laboratories, New York). Cells were washed three times in HBSS, counted and suspended to $10^{7}$ cells per mL of HBSS. Typically, more than $90 \%$ of the exudative cells were intact, viable macrophages.

Bioassay of TNF: Bioactive TNF in culture supernatants was assayed by its cytotoxicity on a confluent culture of a TNF-sensitive L929 cell line in the presence of actinomycin D (17). Briefly, $100 \mu \mathrm{L}$ volumes contain- 

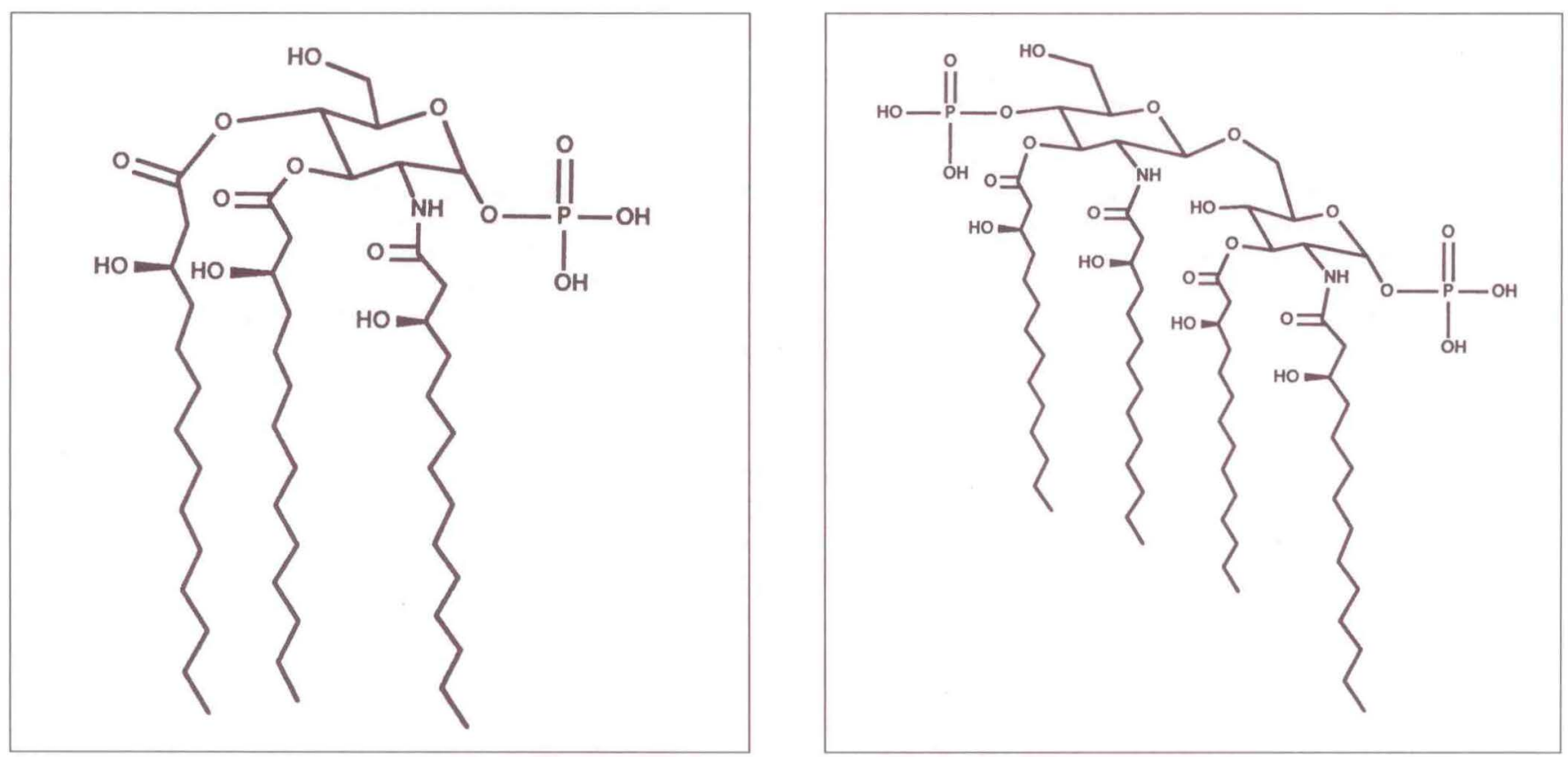

Figure 1) Chemical structures of SDZ MRL 953 (left) and lipid A from Escherichia coli (right)

ing $3 \times 10^{4}$ L929 cells in RPMI 1640 containing 10\% fetal calf serum (FCS) were plated in 96-well plates and cultured overnight to establish a monolayer. Serial dilutions of culture supernatants were directly performed in the wells containing the monolayers. One hundred microlitre volumes of RPMI 1640 containing $10 \% \mathrm{FCS}$ and $2 \mu \mathrm{g}$ actinomycin D were added and the cultures incubated for $18 \mathrm{~h}$. The surviving cells were fixed, stained with Giemsa and dissolved in 50\% 1methyl-2-pyrolidon (Merck, Darmstadt, Germany). The absorbance was read in a Titertek (Easy Reader, SLT Lab Instruments; Vienna, Austria) reader at $590 \mathrm{nM}$. One unit of TNF activity was defined as the reciprocal of the dilution required to produce a $50 \%$ decrease in absorbance relative to control L-929 cells exposed to actinomycin D alone. A neutralizing polyvalent antimouse TNF antibody (Bender; Vienna, Austria) was used to verify the specificity of the TNF bioassay.

Assay of the lethal effects of LPS in D-galactosamine loaded mice: The lethality of SDZ MRL 953 or LPS was evaluated by the method of Galanos et al (18). Briefly, groups of 10 mice (C57BL/6) were simultaneously injected intraperitoneally with D-galactosamine (400 mg/ $\mathrm{kg}$ ) and intravenously with the lipid A analogue or LPS. The $50 \%$ lethal dose (LD50) was calculated by probit analysis (19). The ability of the compound or LPS to induce hyporesponsiveness to the lethal challenge in experimental animals was investigated in animals that had received the appropriate dose of the toleranceinducing agent as a single or multiple dose treatment. Experimental infection: $\mathrm{B}_{6} \mathrm{D}_{2} \mathrm{~F}_{1}$ female mice were rendered neutropenic by a single subcutaneous injection of cyclophosphamide $(200 \mathrm{mg} / \mathrm{kg})$ on day 4 before microbial inoculation. From days 3 through 1 before inoculation, 10 mice were randomly divided into test groups and received serial dilutions of SDZ MRL 953 or LPS (intraperitoneally or intravenously) in $0.2 \mathrm{~mL}$ amounts per mouse as a single or multiple treatment. On day 0 , the animals were inoculated intravenously with a lethal dose of test microorganisms. The $50 \%$ effective doses (ED50) of the test substances were calculated by probit analysis (19) from survival data four days post inoculation.

Statistics: Data are presented as mean \pm SEM unless otherwise stated. ED50 were calculated by probit analysis (19). Survival comparisons were made by Fisher's exact test.

\section{RESULTS}

The onset of the protective efficacy of SDZ MRL 953 against LPS lethality in D-galactosamine-treated mice: Pretreatment with LPS has been shown repeatedly to protect experimental animals against subsequent LPS lethality. To be effective, the tolerance-inducing dose of LPS must be administered at least $1 \mathrm{~h}$ before LPS challenge (10). To determine whether SDZ MRL 953 can provide protection against an otherwise lethal dose of LPS, groups of mice were given various graded doses of the lipid A analogue or saline. At 0, 2, 24 or $72 \mathrm{~h}$ after the pretreatment, the animals were challenged with 500 $\mathrm{ng} / \mathrm{kg}$ of LPS plus $400 \mathrm{mg} / \mathrm{kg}$ of D-galactosamine. Survival was monitored over two days. Table 1 shows the cumulative results of several experiments carried out at different times. It can be seen that as little as $24 \mu \mathrm{g} / \mathrm{kg}$ of SDZ MRL 953 provided 50\% protection against endotoxin lethality in the D-galactosamine mouse model within $2 \mathrm{~h}$ of the pretreatment. Protective effect of SDZ MRL 953 was greatest at $2 \mathrm{~h}$ and was still delectable at 
TABLE 1

Effect of single pretreatments with SDZ MRL 953 on the lethal effects of lipopolysaccharides in D-galactosamine-loaded mice*

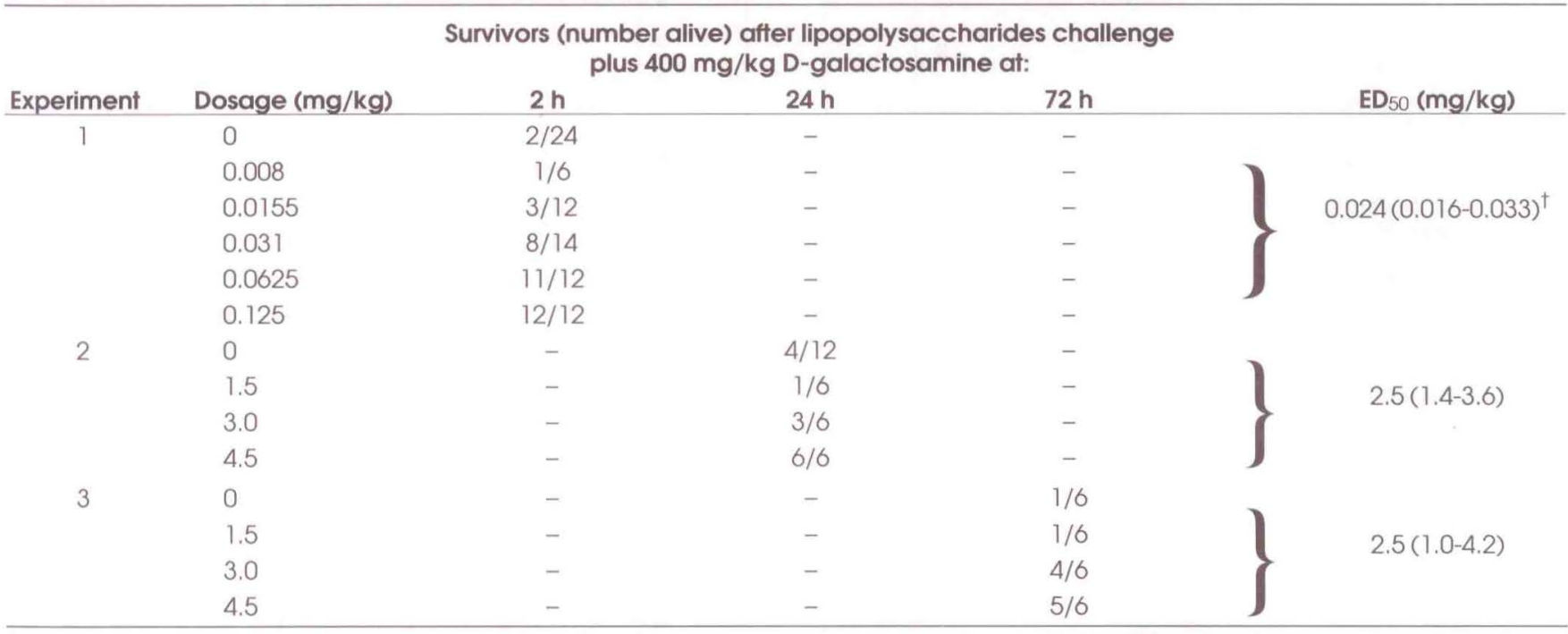

"SDZ MRL 953 was administered as a single intravenous injection before intravenous challenge with LPS 500 ng/kg plus intraperitoneal injection of D-galactosamine $(400 \mathrm{mg} / \mathrm{kg})$ at 2,24 or $72 \mathrm{~h}$ after pretreatment; ${ }^{\dagger}$ Confidence limits from probit analysis are shown in parentheses

24 or $72 \mathrm{~h}$ after administration of the compound. The induced tolerance persisted for up to seven days. No protection was observed when the analogue was administered either simultaneously or after LPS challenge. Effect of repeated dosing with SDZ MRL 953 on the resulting tolerance to the lethal effects of endotoxin: Table 2 shows the effect of the multiple treatment of mice with SDZ MRL 953 on their resistance to the lethal dose of LPS in the D-galactosamine mouse model. Tolerance induced by a single prophylactic dose of the lipid A analogue was significantly improved when the same amount of compound was divided into three equal treatments given on consecutive days. Tolerance was also induced by administering the compound in increasing doses. Again, the induced tolerance persisted for up to seven days after the last treatment.

Production of TNF in vitro by macrophages from 'tolerized' mice: Macrophages are thought to be the cells which mediate the lethal effects of LPS $(3,11,20)$ and Gram-negative bacteria (21). To examine whether SDZ MRL 953-induced resistance to the lethal effects of LPS was related to the macrophage hyporesponsive state to LPS, TNF production by thioglycolate-elicited peritoneal macrophages from tolerized animals was examined ex vivo. As shown in Figure 2, LPS-stimulated macrophages from SDZ MRL 953-tolerized mice produced only a fraction of the TNF that was produced by cells from control animals. The induced hyporesponsiveness was partially reversed by increasing the stimulating dose of LPS in vitro. The onset of the SDZ MRL 953-induced hyporesponsive state paralleled the expression of resistance to the lethal effects of LPS in galactosamine-loaded mice.
Protection against experimental infections: To examine whether the regimens for inducing tolerance to the lethal effects of LPS by SDZ MRL 953 did not compromise the ability of the compound to induce nonspecific resistance to microbial infections, tolerized animals were challenged with $S$ aureus $\left(3.2 \times 10^{8} \mathrm{cfu}\right.$ per mouse). The results show that tolerized mice were resistant to microbial inoculation (Figure 3). However, single doses of the lipid A analogue were less effective than the same amount divided into three doses. For example, whereas single pretreatments with SDZ MRL 953 were protective in $S$ aureus infection with an ED50 of 1.1 $\mathrm{mg} / \mathrm{kg}$ (confidence limits 0.6 to 1.8 ), a similar protective effect was observed at an ED50 of only $0.04 \mathrm{mg} / \mathrm{kg}$ (confidence limits 0.02 to 0.07 ) when the lipid A analogue was administered on three consecutive days.

\section{TABLE 2}

Effect of multiple treatments with SDZ MRL 953 on lethal effects of lipopolysaccharides in D-galactosamineloaded mice*

\begin{tabular}{|c|c|c|c|c|}
\hline \multicolumn{3}{|c|}{$\begin{array}{l}\text { Pretreatment regimen } \\
\text { dosage }(\mathrm{mg} / \mathrm{kg})\end{array}$} & \multirow{2}{*}{$\begin{array}{l}\text { Total dosage } \\
(\mathrm{mg} / \mathrm{kg})\end{array}$} & \multirow[b]{2}{*}{ Survivors ${ }^{\dagger}$} \\
\hline First & Second & Third & & \\
\hline- & - & - & 0 & $1 / 6$ \\
\hline 0.15 & 0.6 & 1.8 & 2.55 & $3 / 6$ \\
\hline 0.3 & 1.25 & 5.0 & 6.25 & $6 / 6$ \\
\hline 1.25 & 2.50 & 5.0 & 8.75 & $5 / 6$ \\
\hline 2.30 & 5.0 & 10.0 & 17.30 & $6 / 6$ \\
\hline
\end{tabular}

*Graded dosages of SDZMRL 953 were given by intraperitoneal route on three consecutive days. Twenty-four hours after the last treatment, animals were challenged with intravenous $500 \mathrm{ng} / \mathrm{kg}$ lipopolysaccharides plus intraperitoneal $400 \mathrm{mg} / \mathrm{kg} D$-galactosamine; ${ }^{\prime}$ Total number alive after lipopolysaccharide challenge plus $400 \mathrm{mg} / \mathrm{kg}$ D-galactosamine $24 \mathrm{~h}$ after third treatment 


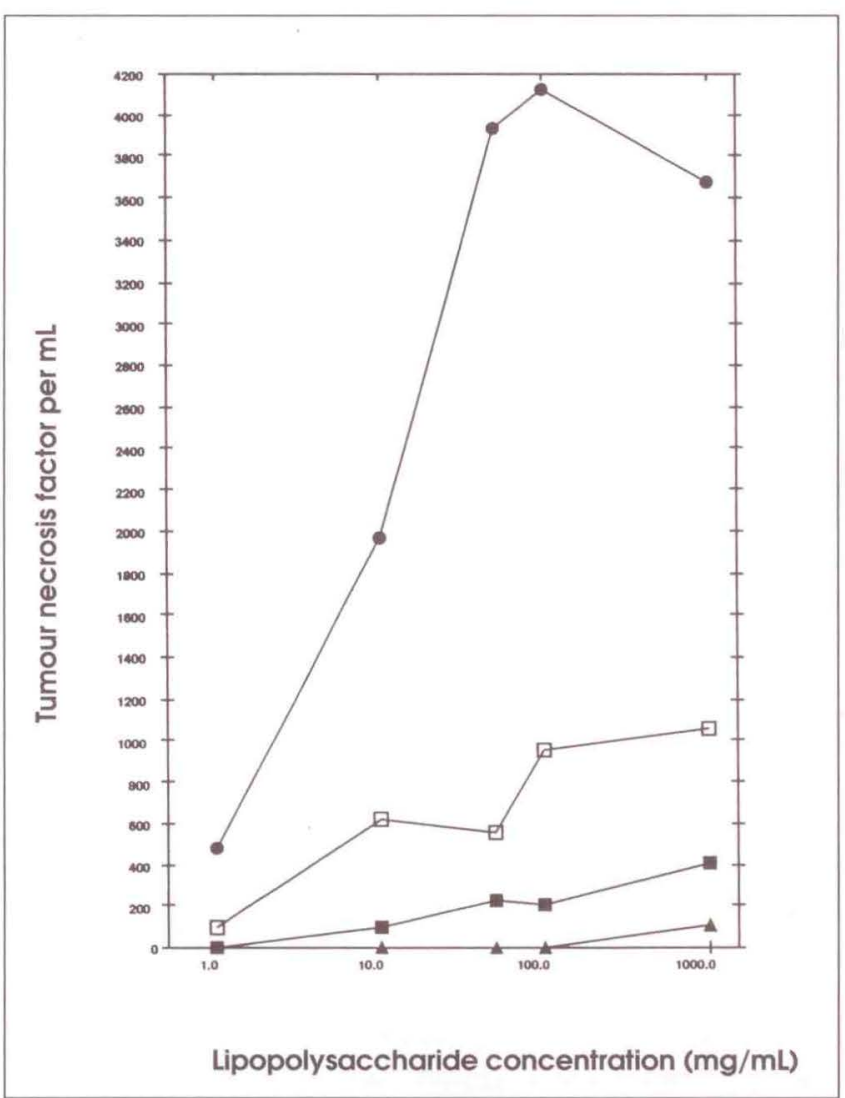

Figure 2) In vitro production of tumour necrosis factor (TNF) by macrophages from SDZ MRL 953-tolerized mice in response to lipopolysaccharide (LPS). Groups of six mice were treated with SDZ MRL 953 (250 $\mu \mathrm{g} /$ mouse) (무), LPS (5 $\mu \mathrm{g} /$ mouse () or placebo (-) once on day $1(\square, \bullet)$ or two times on days 2 and 1 (-A) prior to peritoneal lavage. The macrophages were plated out at $10^{6}$ per well in a costar plate and stimulated with various concentrations of LPS for $4 \mathrm{~h}$ at $37^{\circ} \mathrm{C}$. TNF titres in the culture supernatants were estimated by the L-929 cell assay

\section{Microbicidal capacity of peritoneal macrophages} from SDZ MRL 953-tolerized mice: To examine the mechanisms for the increased resistance to microbial infections, peritoneal exudate cells were tested for their ability to kill an isolate of $E$ coli in vitro. In contrast to the hyporesponsiveness to LPS, macrophages from tolerized mice killed the test organisms better than cells from control animals (Figure 4). Repeated treatment further enhanced the killing capacity of the macrophages over that exhibited by cells from animals which received only a single injection of the analogue. Together, the results indicate that the ability of macrophages to respond to LPS with production of TNF is diminished by repeated administration of SDZ MRL 953 while the killing of bacteria is enhanced.

\section{DISCUSSION}

Gram-negative sepsis remains a clinical problem in myelosuppressed patients or individuals undergoing immunosuppressive therapy. Antimicrobial therapy alone often is ineffective and may provoke the release of LPS from dying Gram-negative organisms $(22,23)$.

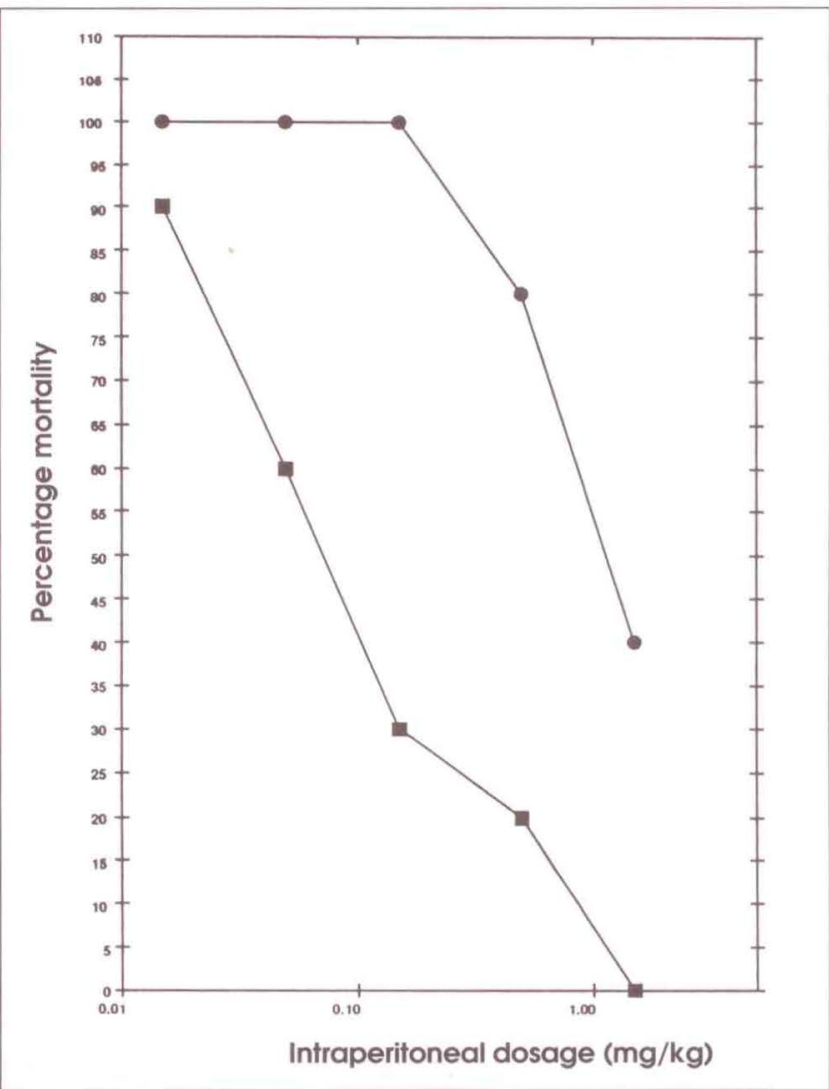

Figure 3) Comparative efficacy of single and repeated ad ministrations of SDZ MRL 953 against fatal Staphylococcus aureus infection. Mice were rendered myelosuppressed by a single subcutaneous injection of cyclophosphamide $(200 \mathrm{mg} / \mathrm{kg})$ four days prior to intravenous inoculation with $\mathrm{S}$ aurueus. SDZ MRL 953 (total dosage $250 \mu \mathrm{g} /$ mouse) was given as a single dose intraperitoneally on day 1 (-) or repeated treatments on days 3, 2 and 1 (total dose divided into three treatments) (n) prior to infection. Survivors were recorded on day 4 post infection

There is a growing consensus that LPS provokes shock and tissue injury by eliciting the release of putative mediators of shock such as interleukin- 1 and TNF- $\alpha$ from stimulated macrophages $(3,11,24)$. Both cytokines can reproduce the symptoms of septic shock and can act synergistically to cause tissue damage and death $(3,6,19,21,25)$. In view of the limited effectiveness of current approaches in treating Gram-negative bacterial diseases (1-3), a number of attempts to interrupt the sequence of events that culminates in shock by passive immunotherapy directed against LPS or pro-inflammatory cytokines is receiving considerable interest as potential supplements to appropriate antimicrobial therapy (3). However, it often is difficult to determine the most appropriate timing and frequency for administering such antibodies to prevent full-blown sepsis.

An alternative approach, which has not yet been exploited in humans, is the induction of an hyporesponsive state against the lethal effects of LPS by nontoxic lipid A analogues. The data presented here provide strong evidence that SDZ MRL 953, a synthetic lipid A substructure analogue, can induce tolerance to 
an otherwise lethal dose of LPS. Hence, administration of the lipid A analogue either as single or multiple treatments to mice induced a dose-dependent hyporesponsiveness to the lethal effects of LPS. It developed within $2 \mathrm{~h}$ of pretreatment and was still detectable up to seven days after the pretreatment. Optimal tolerizing regimens consisted of multiple treatment with either the same dose given daily for three days or increasing daily doses over three days. Similar effects were also induced by monophosphoryl lipid A (MPLA) as evidenced by a diminished LPS-induced colony stimulating factor production $(25,26)$ and a significant increase in resistance to the lethal effects of LPS (26). SDZ MRL 953 is thus the first monosaccharidic derivative of lipid A which appears to be endowed with the ability of LPS to induce the phenomenon of early-phase tolerance against LPS toxicity. These findings support the initial idea that early LPS tolerance is inducible with serologically unrelated types of LPS (8), confirmed with MPLA $(25,26)$ and here by a monosaccharidic lipid A substructure analogue.

The mechanisms by which SDZ MRL 953 induces resistance to lethal effects of LPS, like that of the well-described phenomenon of LPS tolerance $(10,27$, 28), involve a decreased responsiveness of host macrophages to LPS stimulus. Hence, macrophages from tolerized mice produced significantly less TNF in response to LPS ex vivo than cells from control animals. The induced hyporesponsive state was not permanent and was overcome by increasing the concentration of the stimulating LPS. Again, optimal hyporesponsiveness occurred in cells from animals which received SDZ MRL 953 on three consecutive days. These findings are in accordance with a number of reports showing that macrophages from tolerant animals or after incubation with LPS in vitro produced depressed levels of soluble factors when exposed to LPS $(6,7,9,11,12,27)$. Thus, the failure to produce adequate amounts of putative mediators of shock is likely to underlie the observed resistance.

While tolerance induced by SDZ MRL 953 to the lethal effects of LPS may have relevance for the prophylactic treatment of shock, there was a concern that the tolerance-inducing regimens may interfere with the clearance of infectious organisms by macrophages. No evidence was obtained in the present study which indicates that the development of tolerance to LPS also downregulated the ability of SDZ MRL 953 to enhance host resistance against infections. On the contrary, mice which were made tolerant by multiple dose treatment with SDZ MRL 953 were more resistant to Pseudomonas aeruginosa and $S$ aureus infections than animals which were tolerized by a single dose of the analogue. For example, whereas single pretreatments with SDZ MRL 953 were protective against $S$ aureus infection with an $\mathrm{ED}_{50}$ of $1.1 \mathrm{mg} / \mathrm{kg}$, a similar protective effect was observed at an ED50 of only $0.04 \mathrm{mg} / \mathrm{kg}$ when the

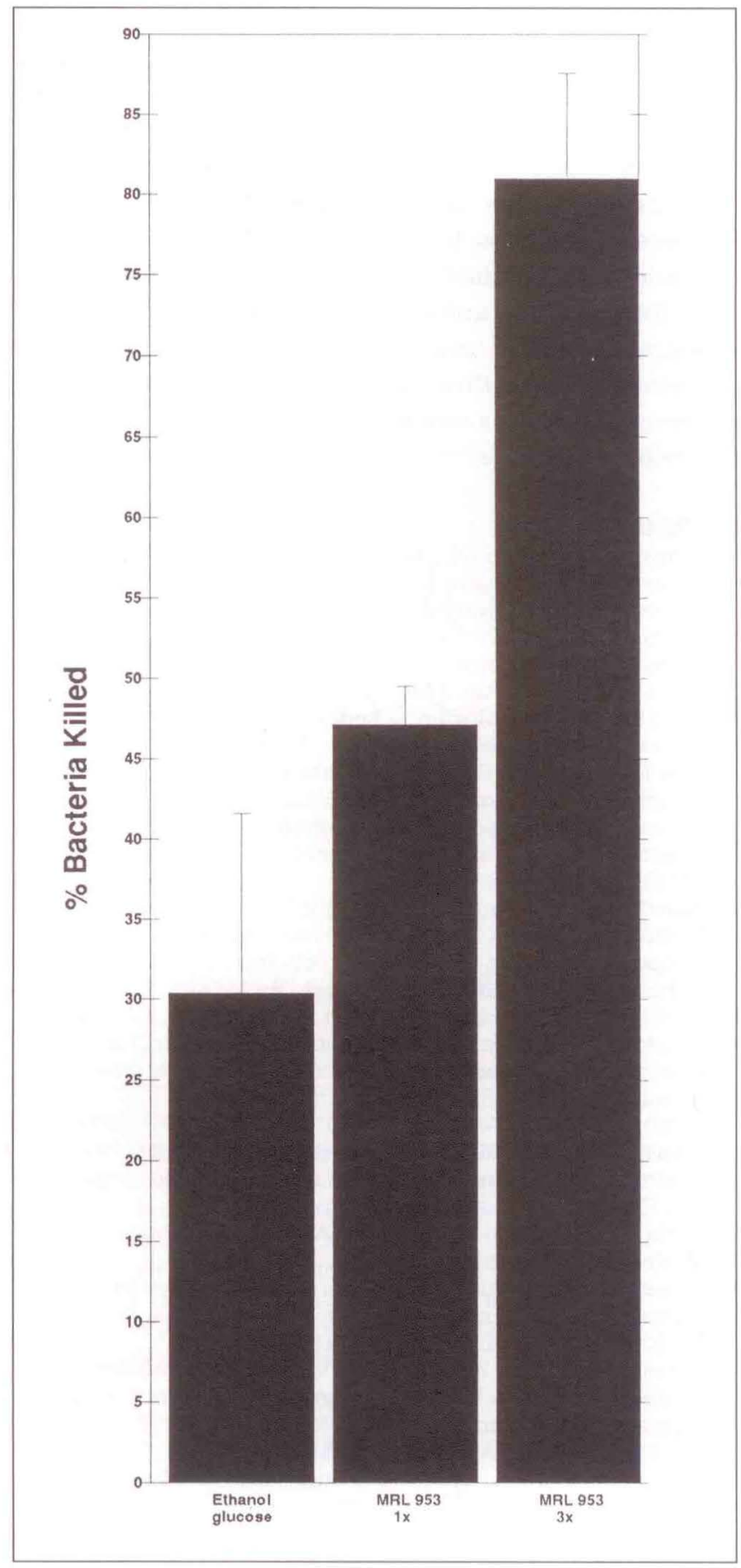

Figure 4) Microbicidal capacity of peritoneal macrophages harvested from mice treated with SDZMRL 953 as single or multiple dose treatment. SDZ MRL 953 was injected intraperitoneally to groups of six mice either once $(1 \times 250 \mu \mathrm{g} /$ mouse $)$ on day 1 or three times (total dosage $250 \mu \mathrm{g} /$ mouse) on days 3, 2 and 1 prior to peritoneal lavage. Escherichia coli was opsonized in 50\% normal human serum and were added to the macrophages at a ratio of 1 . The mixtures were incubated for $4 \mathrm{~h}$ at $37^{\circ} \mathrm{C}$ before the surviving organisms were estimated by plating out 10-fold dilutions of cellular lysates on trypticase soy agar plates. Cumulative data from three separate experiments are shown

compound was administered on three consecutive days prior to infection. These data extend the original work of Berger and Fukui (29) who showed that the increased resistance to infections produced by LPS administra- 
tion was the only known property of LPS to which tolerance did not develop. As shown here, a similar effect can also be obtained by a lipid A analogue substructure. The mechanisms by which tolerized mice exhibit enhanced resistance to infections are not clear. The results of this study suggest that, despite their hyporesponsiveness to LPS, macrophages from tolerized mice killed an isolate of $E$ coli more effectively than cells from control animals. Also, the increased resistance to infection seen after multiple treatment was associated with further enhanced microbicidal capacity observed following a single dose of the lipid A analogue, suggesting that other mechanisms may also be involved.

\section{REFERENCES}

1. Kreger BE, Craven DE, McCabe WR. Gram-negative bacteremia. IV. Re-evaluation of clinical features and treatment in 612 patients. Am J Med 1980;68:344-55.

2. Pizzo PA, Young LS. Limitations of current antimicrobial therapy in the immunosuppressed host: Looking at both sides of the coin. Am J Med 1984;76:101-7.

3. Beutler B. The explosion of septic shock. Curr Opin Infect Dis 1990;3:623-7.

4. Nys M, Cloes JM, Demonty J, Joassin L. Protective effects of polyclonal sera and of monoclonal antibodies active to Salmonella minnesota Re595 lipopolysaccharide during experimental endotoxemia. J Infect Dis 1990;162:1087-95.

5. Morrison DC, Silverstein R, Bright SW, Chen T-Y, Flebbe LM, Lei M-G. Monoclonal antibody to mouse lipopolysaccharide receptor protects mice against the lethal effects of endotoxin. J Infect Dis 1990;1 62:1062-8.

6. Mathison JC, Virca GD, Wolfson E, Tobias PS, Glaser K. Ulevitch RJ. Adaptation to bacterial lipopolysaccharide controls lipopolysaccharide-induced tumor necrosis factor production in rabbits. J Clin Invest 1990;85:1108-18.

7. Ulevitch RJ, Schumann RR, Mathison JC, et al. Endogenous antiendotoxin mechanisms. In: Baumgartner JD, Calandra T, Carlet J, eds. Endotoxin from Pathophysiology to Therapeutic Approaches. Paris: Médecine-Sciences, 1990:31-41.

8. Griesman SE. Induction of endotoxin tolerance. In: Nowotny A, ed. Beneficial Effects of Endotoxins. New York: Plenum Publishing Corp, 1983:149-79.

9. Haas JG, Thiel C, Blömer K, Weiss EH, Riethmüller G, Ziegler-Heitbrock HWL. Downregulation of tumor necrosis factor expression in the human Mono-Mac- 6 cell line by lipopolysaccharide. J Leuk Biol 1989;46:11-4.

10. Freundenberg MA, Galanos C. Induction of tolerance to lipopolysaccharide (LPS)-D-galactosamine lethality by pretreatment with LPS is mediated by macrophages. Infect Immun 1988:56:1352-7.

11. Fraker DL, Stovroff MC, Merino MJ, Norton JA. Tolerance to tumor necrosis factor in rats and the relationship to endotoxin tolerance and toxicity. J Exp Med 1988; 168:95-105.

12. Haslberger A, Sayers T, Reiter H, Chung J, Schütze E. Reduced release of TNF and PCA from macrophages of tolerant mice. Circ Shock 1988;26:185-92.

13. Kotani S, Takada H, Tsujimoto M, et al. Synthetic lipid A with endotoxic and related biological activities comparable to those of a natural lipid A from an Escherichia coli re-mutant. Infect Immun 1985;49:225-37.

14. Stütz PL, Aschauer H, Hildebrandt J, et al. Chemical synthesis of endotoxin analogues and some structure activity relationships. In: Nowotny A, Spitzer JJ, Ziegler EJ, eds. Cellular and Molecular Aspects of Endotoxin Reactions. Amsterdam: Elsevier Science Publishers, 1990:129-44.

15. Lam C, Schütze E, Hildebrandt J, et al. SDZ MRL 953,
The induction of tolerance to LPS by SDZ MRL 953 may have direct relevance to a number of clinical settings that cannot be cured by antibiotics alone. Mathison et al (6) expressed the view that early-phase tolerance to the lethal effects of LPS on macrophages reflects programmed responses that serve to limit host injury while maintaining bacterial killing mechanisms during Gram-negative septicemia. The present results are the first experimental evidence in support of such an hypothesis. Prophylactic application of the compound to patients at risk may improve survival and outcome in both sepsis and patients undergoing immunosuppressive therapy.

a novel immunostimulatory monosaccharidic lipid A analogue with improved therapeutic window in experimental sepsis. Antimicrob Agents Chemother 1991;35:500-5.

16. Lam C, Schütze E, Liehl E, Stütz P. Effect of SDZ MRL 953 on the survival of mice with advanced sepsis that cannot be cured by antibiotics alone. Antimicrob Agents Chemother 1991;35:506-11.

17. Sayers TJ, Macher I, Chung J, Kugler E. The production of tumor necrosis factor by mouse bone marrow-derived macrophages in response to bacterial lipopolysaccharide and a chemically synthesized monosacchadde precursor. J Immunol 1987;138:2935-40.

18. Galanos C, Freundenberg MA, Reutter W. Galactosamineinduced sensitization to the lethal effects of endotoxin. Proc Natl Acad Sci USA 1979;76:5939-43.

19. Miller LC, Tainter ML. Estimation of ED50 and its error by means of logarithmic-probit graph paper. Proc Soc Exp Biol Med 1944;57:261-4.

20. Ohlsson K, Björk P, Bergenfedt M, Hageman R, Thompson RC. Interleukin-1 receptor anatagonist reduces mortality from endotoxin shock. Nature 1990;348:550-2.

21. Filkins JP. Monokines and the metabolic pathophysiology of septic shock. Fed Proc 1985;44:300-4.

22. Shenep JL, Flynn PM, Barrett FF, Stidham GL, Westenkirchner DF. Serial quantitation of endotoxemia and bacteremia during therapy from Gram-negative bacterial sepsis. J Infect Dis 1988; 157:565-8.

23. Shenep JL. Morgan KA. Kinetics of endotoxin release during antibiotic therapy for experimental gram-neagtive bacterial sepsis. J Infect Dis 1984;150:380-8.

24. Henricson BE, Benjamin WR, Vogel SN. Differential cytokine induction by doses of lipopolysaccharide and monophosphoryl lipid A that result in equivalent early endotoxin tolerance. Infect Immun 1990;58:2429-37.

25. Vogel SN, Kaufman EN, Tate MD, Neta R. Recombinant interleukin- $1 \alpha$ and recombinant tumor necrosis factor $\alpha$ synergize in vivo to induce early endotoxin tolerance and associated hematopoietic changes. Infect Immun 1988;56:2650-7.

26. Madonna GS, Peterson J, Ribi E, Vogel SN. Early-phase endotoxin tolerance: Induction by a detoxified lipid A derivative, monophosphoryl lipid A. Infect Immun 1986;52:6-11.

27. Virca GD, Kim SY, Glaser KB, Ulevitch RJ Lipopolysaccharide induces hyporesponsiveness to its own action in RAW 264.7 cell. J Biol Chem 1989;264:21951-6.

28. Mathison JC, Wolfson E, Ulevitch RJ. Participation of tumor necrosis factor in the mediation of gram negative bacterial lipopolysaccharide-induced injury in rabbits. J Clin Invest 1988;81:1925-37.

29. Berger FM, Fukui GM. Endotoxin induced resistance to infections and tolerance. Proc Soc Exp Biol Med 1963;114:780-3. 


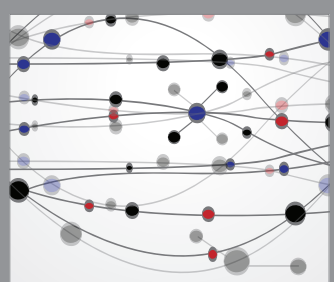

The Scientific World Journal
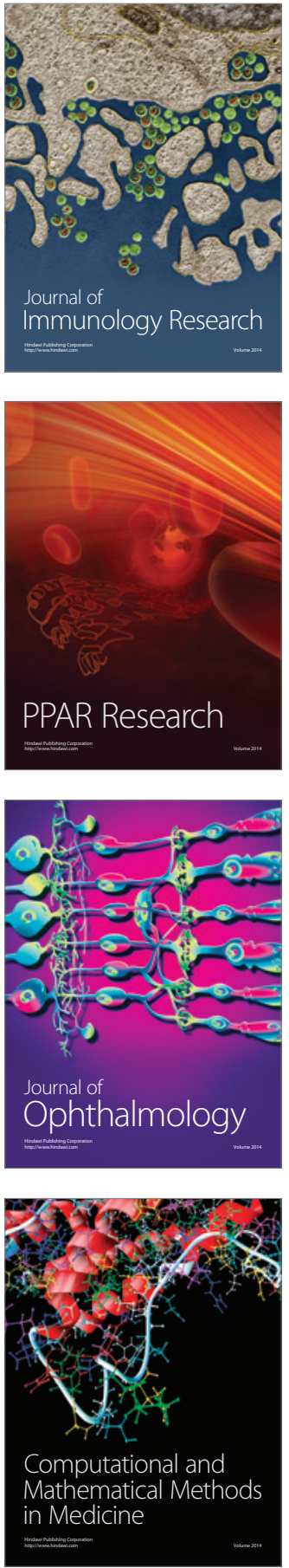

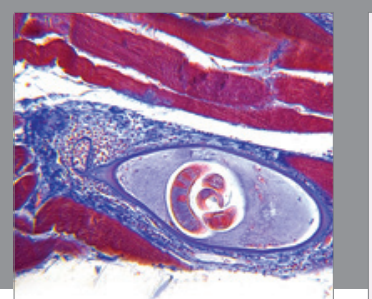

Gastroenterology Research and Practice

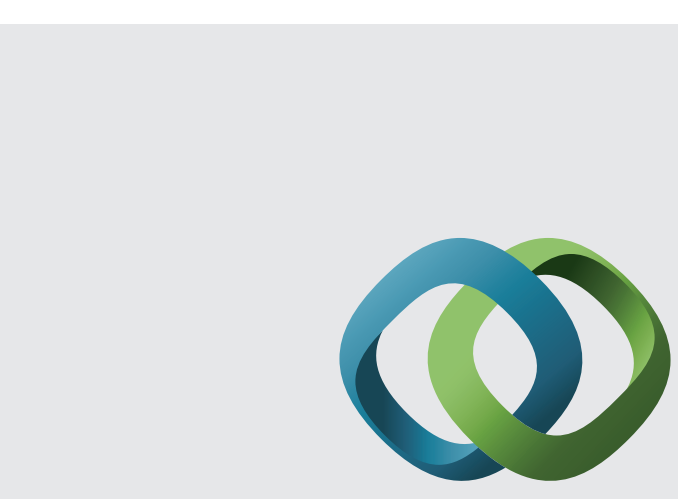

\section{Hindawi}

Submit your manuscripts at

http://www.hindawi.com
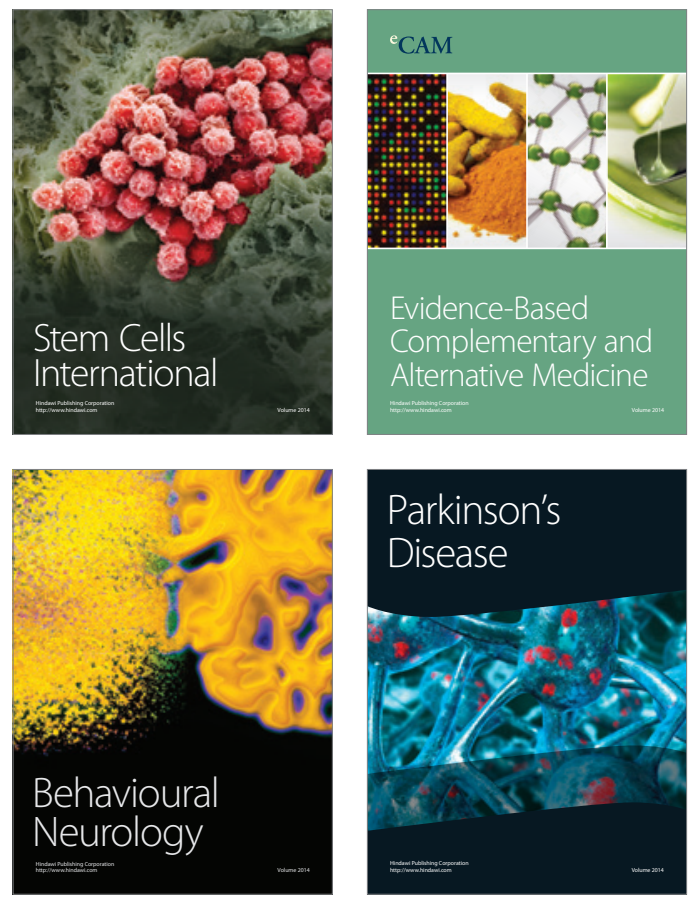
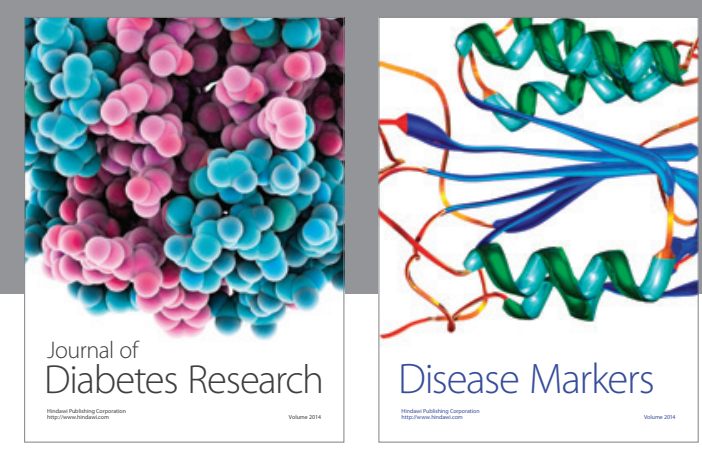

Disease Markers
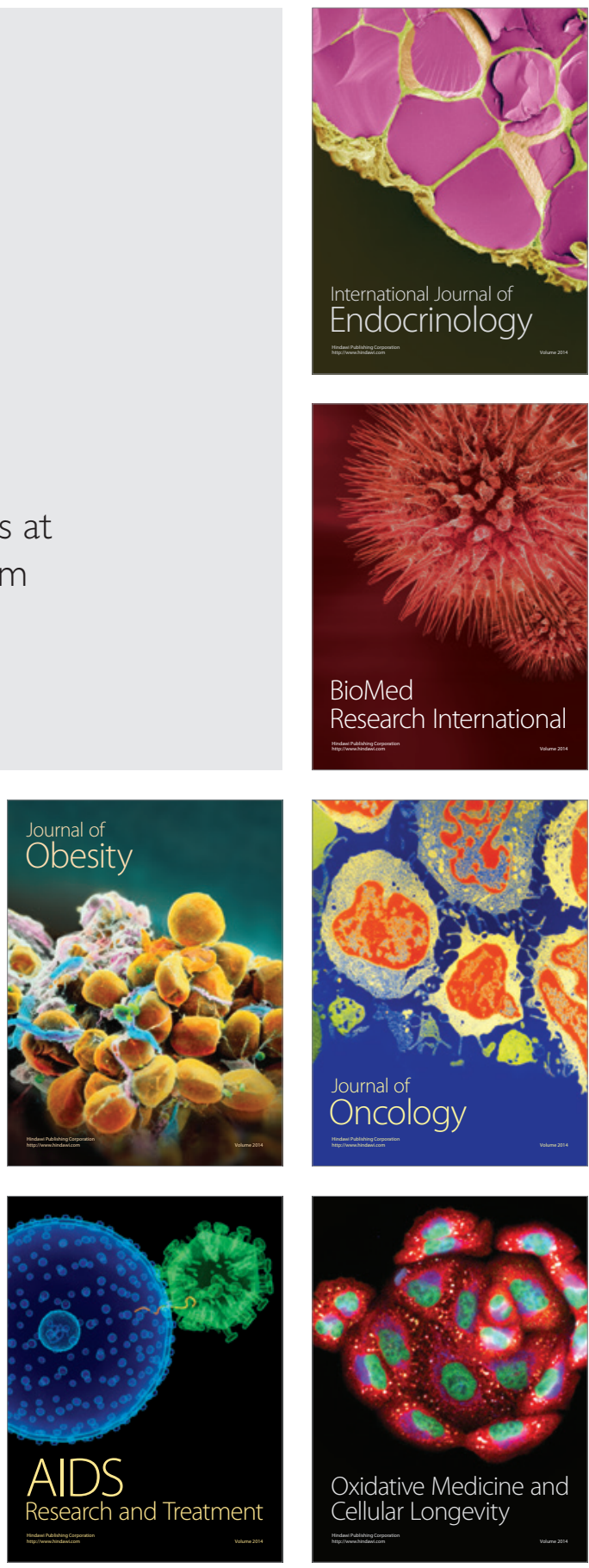